\title{
A Hybrid Approach for Predition of Machining Performances of Glass Fiber Reinforced Plastic (Epoxy) Composites
}

\section{P. Raveendran}

Mahath Amma Institute of Engineering and Technology

S. V. Alagarsamy ( $\sim$ s.alagarsamy88@gmail.com )

Mahath Amma Institute of Engineering and Technology https://orcid.org/0000-0002-6564-0346

C. Chanakyan

Government College of Engineering

M. Meignanamoorthy

K. Ramakrishnan College of Engineering

M. Ravichandran

K. Ramakrishnan College of Engineering

S. Sakthivelu

Mount Zion College of Engineering and Technology

\section{Research Article}

Keywords: GFRP, End milling, Taguchi method, GRA, DFA, ANOVA

Posted Date: June 24th, 2021

DOl: https://doi.org/10.21203/rs.3.rs-651375/v1

License: (9) (i) This work is licensed under a Creative Commons Attribution 4.0 International License.

Read Full License 


\title{
A Hybrid Approach for Predition of Machining Performances of Glass Fiber Reinforced Plastic (Epoxy) Composites
}

\author{
P.Raveendran ${ }^{1}$, S.V. Alagarsamy ${ }^{1 *}$, C. Chanakyan ${ }^{2}$, M.Meignanamoorthy ${ }^{3}$, M. \\ Ravichandran $^{3}$ and S.Sakthivelu ${ }^{4}$ \\ ${ }^{1}$ Department of Mechanical Engineering, Mahath Amma Institute of Engineering and \\ Technology, Pudukkottai-622 101, Tamil Nadu, India, \\ ${ }^{2}$ Department of Mechanical Engineering, Government College of Engineering, \\ Thanjavur-613 402, Tamil Nadu, India \\ ${ }^{3}$ Department of Mechanical Engineering, K. Ramakrishnan College of Engineering, \\ Trichy-621 112, Tamil Nadu, India \\ ${ }^{4}$ Department of Mechanical Engineering, Mount Zion College of Engineering and \\ Technology, Pudukkottai-622 507, Tamil Nadu, India \\ Corresponding author e-mail: s.alagarsamy88@gmail.com
}

\begin{abstract}
In recent years, Glass Fiber Reinforced Plastic (GFRP) composites are more potential materials for usage in various structural applications in aerospace and automobile industries, owing to its favorable properties, such as light weight, specific strength, high elastic modulus and excellent corrosion resistance. This paper presents a new hybrid approach for multi-objective optimization of machining parameters on GFRP composite using Taguchi coupled grey relational (GR) and desirability function (DF) approach. The end milling of GFRP composite was performed as per Taguchi's L16 orthogonal array by considering three input parameters: viz. cutting speed (V), feed rate (F) and depth of cut (D), each at four levels. The material removal rate (MRR), surface roughness (SR) and tool wear (TW) were chosen as output responses. The main effect plot was used to determine the optimum level of machining parameters on the multiple responses. Moreover, analysis of variance (ANOVA) were applied to examine the significance of the parameters. Based on the ANOVA results, it was been proved that the depth of cut was the most remarkable parameter, trailed by feed rate and cutting speed, respectively. Finally, the confirmation tests exhibited that the DA approach was employed better in terms of determining the optimum level of machining parameters as compared to GR analysis.
\end{abstract}

Key Words: GFRP. End milling. Taguchi method. GRA. DFA. ANOVA. 


\section{Introduction}

In the recent decade technologies, traditional materials have been replaced by composite materials due to low thermal expansion, high strength to light weight ratio, and high modulus [1]. It is also inexpensive and substitutes to stainless steel material. In the recent day, glass fiber reinforced polymer (GFRP) composites have been broadly utilized in various engineering sectors, namely, defense, manufacturing, production units, oil and gas based industries $[2,3]$. Filament winding and hand lay-up methods produce the components of GFRP composites [4]. Once the fabrication of the components was completed, it required to start-up the machining process for dimensional control with simple arrangements. Surface finish and dimensional accuracy are essential attributes for machined surface components while processing GFRP composites machining [5]. The machining outcomes are controlled with MRR, TW, and SR. Reveendran et al. [6] studied the SR and TW of the GFRP composite rod with the TiN coated tool. Depth of cut, cutting feed, and speed are the parameters for the machining process. DF and GR analysis are employed to observe the significant process parameters. Arun Kumar Parida et al. [7] investigated the GFRP composite by turning method to analyze the responses, namely SR and MRR. Taguchi method designed the parameters and analyzed them with the TOPSIS technique for finding the optimal process parameters. The depth of cut was the primary influencing parameter than the other parameters. Hazari Naresh et al. [8] analyzed the unidirectional GFRP composites turning by PCD tool with Taguchi technique. In this research, forces, TW and surface quality are the output responses, and cutting depth, tool movement rate and cutting velocity are the input parameters. An Taguchi L9 array was utilized to find out the better-optimized parameters with the economic condition. Naveen sait et al. [9] presented the turning of GFRP composite pipe by using cemented carbide cutting tool. In this study, depth of cut, feed rate, and cutting velocity are selected as input parameters, and the output responses were namely machining force, crater and flank wear, SR. DFA with Taguchi proves the optimized machining parameters with confirmation level. Jenarthanan et al. [10] exhibits characteristics of the GFRP composites by turning method with the carbide-based tool. In this investigation, helix angle, feed rate, fiber orientation angle, feed rate, and spindle speed are the input parameters. The machining force, SR and delamination factor are selected as an output parameter. The optimizations of machined parameters are analyzed with DF analysis. Palanikumar et al. [11] optimized the machining parameters of GFRP composites utilizing the carbide tool by the Taguchi method. The effect of machining parameters on the responses 
such as cutting pressure, MRR, TW and SR. They reported that machining time was the most important factor to obtain the better responses. Sachin Ghalme et al. [12] optimized the milling parameters on GFRP composites for enhancing the investigational outcomes. Taguchi method was used to predict the SR with contributing input parameters like feed, speed, and cut depth. Atul Sharma et al. [13] investigated the gear accuracy, and SR on GFRP composites by using Taguchi related GR analysis. In this work, Taguchi L27 experiments composed the design with DOE technique. The grey relational grade of 0.8318 was attained at optimum level of parameters. Rajesh Kumar Verma et al. [14] carried out the machining process on the GFRP composites and optimized the process parameters with integrated principal component and fuzzy logic analysis. They concluded that the attributes of the machining parameters are improved by using those methods. The integrated methods are produced fine results than the weighted principal component analysis. Mohammed Yaser et al. [15] proposed the GR and DF analysis on the milled GFRP composites with optimized machining parameters. In this research, DF analysis is a feasible method to optimize the parameters than the other method. Palanikumar et al. [16] observed the improved machining parameters on GFRP composites with carbide tool by Taguchi-based fuzzy logic. In this optimization, multi response performance index was used to analyze the responses, namely SR, TW, and MRR. Similarly, the verification tests were performed by the optimal level of machining process parameters.

Here, the objective of the present investigation is to determine the optimal level of parameters for attaining the higher MRR with low SR and TW, in the end milling process of GFRP composite. A hybrid Taguchi combined GR and DF approach is employed to find out the optimum level of machining parameters. Moreover, ANOVA is used to determine the significant effect of parameters on the desired machining performance.

\section{Materials and Methods}

In this research work, GFRP composite was chosen as a work material which is purchased from Micro Fine Chemicals, Chennai. Glass fibers are excellent raw materials for the production of wide range of composites for different applications. Because of their availability, renewability, low density, price and better mechanical properties make them an attractive fiber used for the manufacturing of composites. The glass fiber-containing composites are used in transportation, military applications, building and construction industries and consumer products [17]. The price of polymer composites reinforced with glass fibers, is two to three times lower than that of other reinforcements polymers which 
make them feasible for composite applications. A work specimen of GFRP composite having dimensions of $150 \mathrm{~mm} \times 100 \mathrm{~mm} \times 10 \mathrm{~mm}$ thick was used. The properties of GFRP composite are depicted in Table 1. The machining work was performed on a CNC vertical machining centre. The high speed steel (HSS) end mill cutter with $6 \mathrm{~mm}$ diameter was used as a cutting tool for milling of GFRP composite. During the milling process, the even depth of slot was maintained at $5 \mathrm{~mm}$ for all the experiments. The plan of present investigation is depicted in Fig. 1.

Table 1. Properties of GFRP composite

\begin{tabular}{|l|l|}
\hline Glass fiber & E-glass \\
\hline Matrix material & Epoxy resin \\
\hline Epoxy content $(\%)$ & $20-25$ \\
\hline Glass content $(\%)$ & $75-80$ \\
\hline Density $\left(\mathrm{g} / \mathrm{cm}^{3}\right)$ & 1.9 \\
\hline Tensile strength $(\mathrm{MPa})$ & 1200 \\
\hline Shear strength $(\mathrm{MPa})$ & 50 \\
\hline
\end{tabular}

To conduct the end milling experiments, four levels of input parameters such as cutting speed (V), feed rate (F) and depth of cut (D) are selected and are depicted in Table 2. The machining was carried out as per L16 orthogonal array, shown in Table 3. Based on the orthogonal design, sixteen experiments were carried out on GFRP composite by using the CNC vertical milling center.

Table 2. Machining parameters and their levels

\begin{tabular}{|c|c|c|c|c|c|c|}
\hline \multirow{2}{*}{ Notation } & \multirow{2}{*}{ Machining parameters } & \multirow{2}{*}{ Units } & \multicolumn{4}{|c|}{ Level } \\
\cline { 5 - 7 } & & & $\mathbf{1}$ & $\mathbf{2}$ & $\mathbf{3}$ & $\mathbf{4}$ \\
\hline V & Cutting speed & $\mathrm{rpm}$ & 200 & 400 & 600 & 800 \\
\hline F & Feed rate & $\mathrm{mm} / \mathrm{min}$ & 20 & 30 & 40 & 50 \\
\hline D & Depth of cut & $\mathrm{mm}$ & 0.5 & 0.8 & 1.2 & 1.6 \\
\hline
\end{tabular}

In this proposed work, the responses such as MRR, SR and TW are considered. The SR was estimated at three location on each machined places by using Mitutoya Talysurf SJ-210 surface roughness tester and the average values are considered. The MRR and TW were determined by using the Eqs. (1) \& (2). 


$$
\begin{aligned}
& M R R=\frac{W_{i}-W_{f}}{T}, g / \min \\
& T W=\frac{T_{i}-T_{f}}{T}, g / \mathrm{min}
\end{aligned}
$$

Where, $W_{i}$ and $W_{f}$ - initial and final weight of the work piece $(g)$, respectively, $T_{i}$ and $T_{f}-$ initial and final weight of the tool $(\mathrm{g})$, respectively, $\mathrm{T}$ - machining time (min). The estimated responses are provided in Table 3.

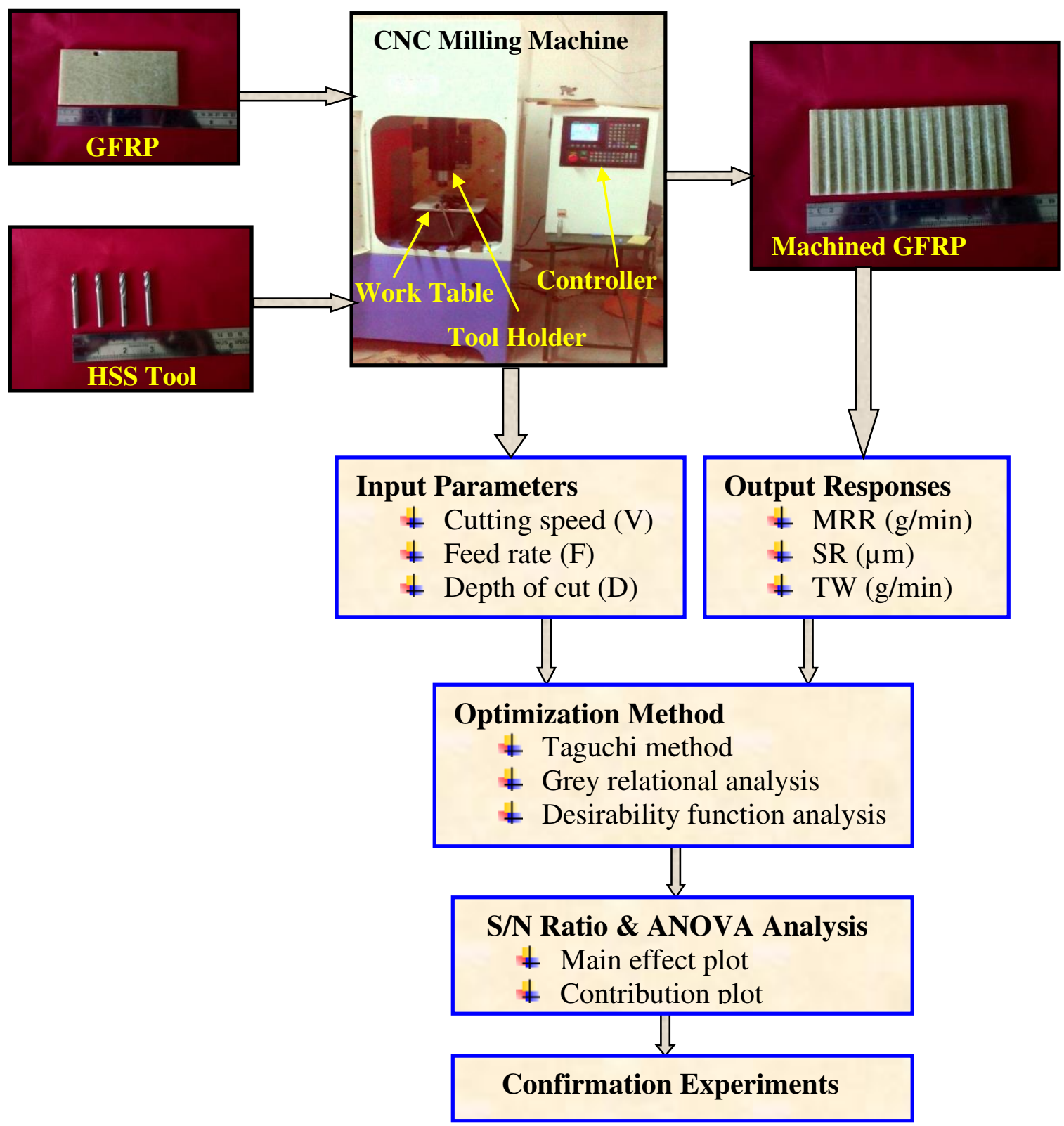

Fig. 1 The work plan of present investigation 
Table 3. L16 orthogonal design of parameters and their output responses

\begin{tabular}{|c|c|c|c|c|c|c|}
\hline Ex. No & $\begin{array}{c}\mathbf{V} \\
(\mathbf{r p m})\end{array}$ & $\begin{array}{c}\mathbf{F} \\
(\mathbf{m m} / \mathbf{m i n})\end{array}$ & $\begin{array}{c}\mathbf{D} \\
(\mathbf{m m})\end{array}$ & $\begin{array}{c}\text { MRR } \\
(\mathbf{g} / \mathbf{m i n})\end{array}$ & $\begin{array}{c}\text { SR } \\
(\boldsymbol{\mu m})\end{array}$ & $\begin{array}{c}\text { TW } \\
(\mathbf{g} / \mathbf{m i n})\end{array}$ \\
\hline 1 & 200 & 20 & 0.5 & 0.2765 & 6.689 & 0.0547 \\
\hline 2 & 200 & 30 & 0.8 & 0.4834 & 6.111 & 0.0053 \\
\hline 3 & 200 & 40 & 1.2 & 0.7721 & 1.798 & 0.0018 \\
\hline 4 & 200 & 50 & 1.6 & 1.1629 & 2.285 & 0.0022 \\
\hline 5 & 400 & 20 & 0.8 & 0.2714 & 1.722 & 0.0034 \\
\hline 6 & 400 & 30 & 0.5 & 0.5434 & 2.181 & 0.0286 \\
\hline 7 & 400 & 40 & 1.6 & 0.9554 & 1.513 & 0.0006 \\
\hline 8 & 400 & 50 & 1.2 & 0.9142 & 2.549 & 0.0071 \\
\hline 9 & 600 & 20 & 1.2 & 0.3285 & 1.514 & 0.0228 \\
\hline 10 & 600 & 30 & 1.6 & 0.3909 & 1.621 & 0.0022 \\
\hline 11 & 600 & 40 & 0.5 & 0.1045 & 2.326 & 0.0058 \\
\hline 12 & 600 & 50 & 0.8 & 0.7209 & 1.878 & 0.0046 \\
\hline 13 & 800 & 20 & 1.6 & 0.3915 & 2.614 & 0.0019 \\
\hline 14 & 800 & 30 & 1.2 & 0.4491 & 3.71 & 0.0012 \\
\hline 15 & 800 & 40 & 0.8 & 0.4487 & 1.908 & 0.0039 \\
\hline 16 & 800 & 50 & 0.5 & 0.3857 & 3.471 & 0.0028 \\
\hline
\end{tabular}

\section{Methodologies and Implementations}

\subsection{Grey Relational Approach}

GR approach is a multi objective optimization method which is employed to determine the optimum level of parameters on the multiple responses [18]. The given steps are to be carried out during the GR analysis:

Step 1 ( $\mathrm{S} / \mathrm{N}$ ratio): If the objective of the response is larger the better, then the $\mathrm{S} / \mathrm{N}$ ratio was calculated in Eq. (3).

$$
\mathrm{S} / \mathrm{N} \text { ratio }=-10 \log _{10}(1 / n) \sum_{k=1}^{n} \frac{1}{Y_{i_{j}}{ }^{2}}
$$

Where $n$ - number of replications, $Y_{i j}$ - observed responses value where $i=1,2,3 \ldots . . n ; j=$ $1,2,3 \ldots \ldots . . . k$. 
If the objective of the response is smaller the better, then the $\mathrm{S} / \mathrm{N}$ ratio was calculated in the Eq. (4).

$$
\mathrm{S} / \mathrm{N} \text { ratio }=-10 \log _{10}(1 / n) \sum_{k=1}^{n} Y_{i j}^{2}
$$

Step 2 (Normalized S/N ratio): If the target value is "larger is better", then the original sequence is normalized as Eq. (5).

$$
x_{i}^{*}(k)=\frac{x_{i}^{(0)}(k)-\min x_{i}^{(0)}(k)}{\max x_{i}^{(0)}(k)-\min x_{i}^{(0)}(k)}
$$

If the target value of the original sequence is "smaller is better", then the original sequence is normalized as Eq. (6).

$$
x_{i}^{*}(k)=\frac{\max x_{i}^{(0)}(k)-x_{i}^{(0)}(k)}{\max x_{i}^{(0)}(k)-\min x_{i}^{(0)}(k)},
$$

Where $x_{i}^{*}(k)$ - is the compatibility sequence, $x_{i}^{(0)}(k)$-is the original sequence of the target value for $i=1,2,3 \ldots, m$ and $k=1,2, \ldots, n$. Table 4 shows the calculated $\mathrm{S} / \mathrm{N}$ ratio and normalized $\mathrm{S} / \mathrm{N}$ ratio for each response.

Step 3 (Grey relational coefficient): In this step, GRC value is calculated from the normalized values by using Eq. (7).

$$
\gamma\left(x_{0}{ }^{*}(k) \cdot x_{i}{ }^{*}(k)\right)=\frac{\Delta \min +\zeta \cdot \Delta \max }{\Delta_{0_{i}}(k)+\zeta \cdot \Delta \max }
$$

Where $\gamma\left(x_{0}{ }^{*}(k) \cdot x_{i}^{*}(k)\right)$ - is the GRC, $\Delta \min \& \Delta \max$ - is a minimum and maximum value of $\Delta_{0 i}(k)$ and $\zeta$ - is distinguishing coefficient $(0.5)$.

Table 4 Calculated $\mathrm{S} / \mathrm{N}$ ratio and normalized $\mathrm{S} / \mathrm{N}$ ratio

\begin{tabular}{|c|c|c|c|c|c|c|}
\hline \multirow{2}{*}{ Ex. No } & \multicolumn{3}{|c|}{ S/N Ratio (dB) } & \multicolumn{3}{c|}{ Normalized S/N Ratio (dB) } \\
\cline { 2 - 7 } & MRR & SR & TW & MRR & SR & TW \\
\hline 1 & -11.17 & -16.51 & 25.234 & 0.1625 & 0.0000 & 0.0000 \\
\hline
\end{tabular}




\begin{tabular}{|l|l|l|l|l|l|l|}
\hline 2 & -6.31 & -15.72 & 45.401 & 0.3580 & 0.1117 & 0.9124 \\
\hline 3 & -2.25 & -5.10 & 54.471 & 0.6307 & 0.9449 & 0.9767 \\
\hline 4 & 1.31 & -7.18 & 53.073 & 1.0000 & 0.8509 & 0.9706 \\
\hline 5 & -11.33 & -4.72 & 49.319 & 0.1576 & 0.9596 & 0.9484 \\
\hline 6 & -5.30 & -6.77 & 30.845 & 0.4147 & 0.8709 & 0.4814 \\
\hline 7 & -0.40 & -3.60 & 64.013 & 0.8039 & 1.0000 & 1.0000 \\
\hline 8 & -0.78 & -8.13 & 42.926 & 0.7650 & 0.7998 & 0.8797 \\
\hline 9 & -9.67 & -3.60 & 32.822 & 0.2116 & 0.9998 & 0.5894 \\
\hline 10 & -8.16 & -4.20 & 52.879 & 0.2705 & 0.9791 & 0.9697 \\
\hline 11 & -19.61 & -7.33 & 44.612 & 0.0000 & 0.8429 & 0.9030 \\
\hline 12 & -2.84 & -5.47 & 46.651 & 0.5824 & 0.9295 & 0.9257 \\
\hline 13 & -8.14 & -8.35 & 54.111 & 0.2711 & 0.7873 & 0.9752 \\
\hline 14 & -6.95 & -11.39 & 57.924 & 0.3256 & 0.5755 & 0.9882 \\
\hline 15 & -6.96 & -5.61 & 48.179 & 0.3252 & 0.9237 & 0.9396 \\
\hline 16 & -8.27 & -10.81 & 50.903 & 0.2656 & 0.6217 & 0.9590 \\
\hline
\end{tabular}

Step 4 (Grey relational grade): GRG is computed by the weighted sum of the GRC. It can be calculated using Eq. (8).

$$
\gamma\left(x_{0}^{*} \cdot x_{i}^{*}\right)=\frac{1}{n} \sum_{k=1}^{n} \gamma\left(x_{0}^{*}(k) \cdot x_{i}^{*}(k)\right)
$$

Where, $\gamma\left(x_{0}{ }^{*} \cdot x_{i}^{*}\right)$ - is the GRC, $\mathrm{n}$-is the number of output responses.

In general, the highest values of GRG represented the optimal combination of parameters in the multiple responses. The calculated GRC and GRG with rank are provided in Table 5.

Table 5 GRC and GRG with rank

\begin{tabular}{|c|c|c|c|c|c|}
\hline \multirow{2}{*}{ Ex. No } & \multicolumn{3}{|c|}{ GRC } & \multirow{2}{*}{ GRG } & \multirow{2}{*}{ Rank } \\
\cline { 2 - 5 } & MRR & SR & TW & & 16 \\
\hline 1 & 0.3738 & 0.3333 & 0.3333 & 0.3468 & 15 \\
\hline 2 & 0.4378 & 0.3601 & 0.8509 & 0.5496 & 3 \\
\hline 3 & 0.5752 & 0.9008 & 0.9555 & 0.8105 & 2 \\
\hline 4 & 1.0000 & 0.7702 & 0.9445 & 0.9049 & 2 \\
\hline
\end{tabular}




\begin{tabular}{|c|c|c|c|c|c|}
\hline 5 & 0.3725 & 0.9253 & 0.9065 & 0.7348 & 6 \\
\hline 6 & 0.4607 & 0.7948 & 0.4909 & 0.5821 & 14 \\
\hline 7 & 0.7183 & 1.0000 & 1.0000 & 0.9061 & 1 \\
\hline 8 & 0.6803 & 0.7141 & 0.8060 & 0.7335 & 7 \\
\hline 9 & 0.3881 & 0.9996 & 0.5491 & 0.6456 & 11 \\
\hline 10 & 0.4067 & 0.9599 & 0.9428 & 0.7698 & 4 \\
\hline 11 & 0.3333 & 0.7610 & 0.8375 & 0.6439 & 12 \\
\hline 12 & 0.5449 & 0.8764 & 0.8706 & 0.7640 & 5 \\
\hline 13 & 0.4069 & 0.7015 & 0.9528 & 0.6871 & 9 \\
\hline 14 & 0.4257 & 0.5409 & 0.9769 & 0.6478 & 10 \\
\hline 15 & 0.4256 & 0.8676 & 0.8922 & 0.7285 & 8 \\
\hline 16 & 0.4051 & 0.5693 & 0.9242 & 0.6328 & 13 \\
\hline
\end{tabular}

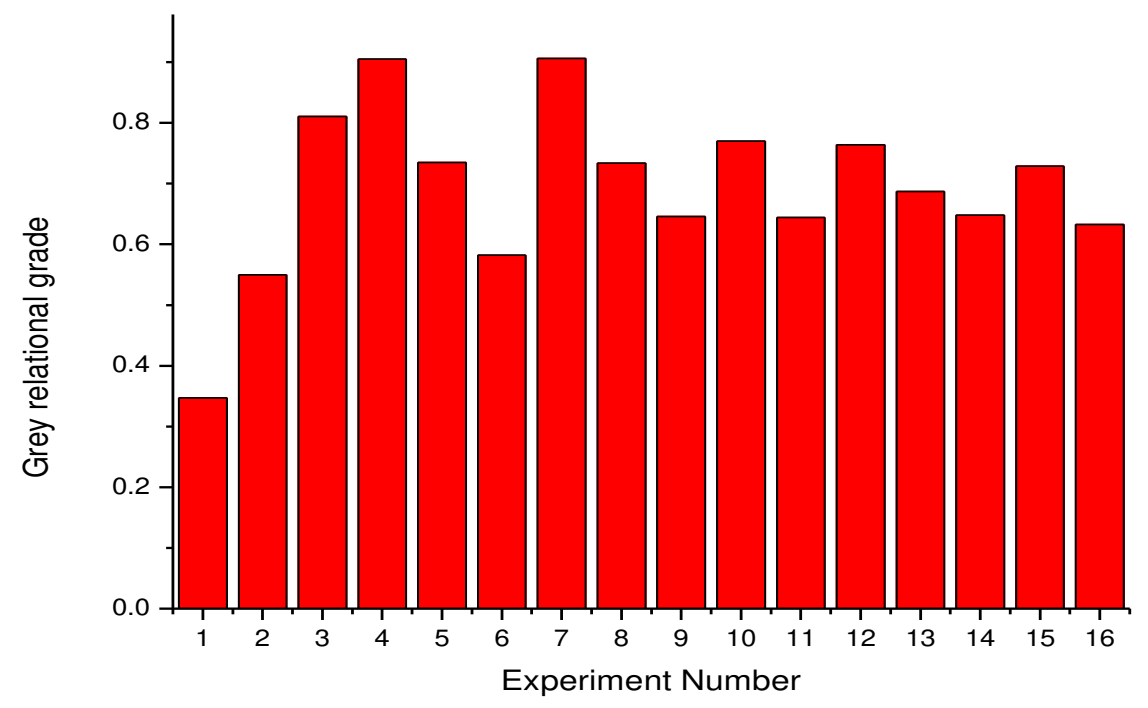

Fig. 2 Rank plot for GRG

Figure 2 exhibits the GRG versus experiment number and it was explored that the Ex. No 7 has a higher GRG (0.9061), which consists of the optimal combination of parameters (cutting speed $-400 \mathrm{rpm}$, feed rate $-40 \mathrm{~mm} / \mathrm{min}$ and depth of cut $-1.6 \mathrm{~mm}$ ) with an objective to maximize the MRR and minimize the SR and TWR for the end milling process of GFRP. 


\subsection{Desirability Function Approach}

DF approach was developed by Derringer and Suich for optimizing the multi-objective problems [19]. This method can be used to convert the multi responses into single responses with the consideration of composite desirability $\left(\mathrm{d}_{\mathrm{G}}\right)$. The following steps are to be taken for the DF analysis:

Step 1 (Individual desirability index, $\mathrm{d}_{\mathrm{i}}$ ): Here, three types of formula are availed for compute the individual desirability index $\left(\mathrm{d}_{\mathrm{i}}\right)$ depending upon the objectives.

Larger-the-better: If the objective of the response is to be maximum the Eq. (9) was used.

$$
d i=\left\{\begin{aligned}
1, & \hat{y} \leq y_{\min } \\
\left(\frac{\hat{y} j-y_{\max }}{y_{\min }-y_{\max }}\right)^{r}, & y_{\min } \leq \hat{y} j \leq y_{\max }, r \geq 0 \\
0, & \hat{y} \geq y_{\max }
\end{aligned}\right.
$$

Smaller-the-better: If the objective of the response is to be minimum the Eq. (10) was used.

$$
d i=\left\{\begin{aligned}
1, & \hat{y} \leq y_{\min } \\
\left(\frac{\hat{y} j-y_{\min }}{y_{\min }-y_{\max }}\right)^{r}, & y_{\min } \leq \hat{y} j \leq y_{\max }, r \geq 0 \\
0, & \hat{y} \geq y_{\max }
\end{aligned}\right.
$$

Where, $y_{\max } \& y_{\min }-$ is the maximum and minimum value of ' $y$ '.

Step 2 (Composite desirability $\left(\mathrm{d}_{\mathrm{G}}\right)$ : To determine the composite desirability value by using Eq. (11).

$$
d G=\sqrt[w]{d 1^{w 1} * d 2^{w 2} * \ldots * d i^{w i}}
$$

Where, $d_{i}-$ is the individual desirability index and $w_{i}$ - is the weight of response.

In general, the larger value of the composite desirability $\left(\mathrm{d}_{\mathrm{G}}\right)$ is chosen for the optimum level of the parameters. The calculated individual and composite desirability with rank is shown in Table 6. 
Table 6 Individual (di) and composite desirability (dG)

\begin{tabular}{|c|c|c|c|c|c|}
\hline \multirow{2}{*}{ Exp. No } & \multicolumn{3}{|c|}{ Individual desirability $\left(d_{i}\right)$} & \multirow{2}{*}{ Composite desirability (dG) } & \multirow{2}{*}{ Rank } \\
\hline & MRR & SR & TW & & \\
\hline 1 & 0.1625 & 0.0000 & 0.0000 & 0.0000 & 15 \\
\hline 2 & 0.3580 & 0.1117 & 0.9124 & 0.3316 & 14 \\
\hline 3 & 0.6307 & 0.9449 & 0.9767 & 0.8350 & 3 \\
\hline 4 & 1.0000 & 0.8509 & 0.9706 & 0.9382 & 1 \\
\hline 5 & 0.1576 & 0.9596 & 0.9484 & 0.5235 & 12 \\
\hline 6 & 0.4147 & 0.8709 & 0.4814 & 0.5581 & 10 \\
\hline 7 & 0.8039 & 1.0000 & 1.0000 & 0.9298 & 2 \\
\hline 8 & 0.7650 & 0.7998 & 0.8797 & 0.8135 & 4 \\
\hline 9 & 0.2116 & 0.9998 & 0.5894 & 0.4996 & 13 \\
\hline 10 & 0.2705 & 0.9791 & 0.9697 & 0.6357 & 7 \\
\hline 11 & 0.0000 & 0.8429 & 0.9030 & 0.0000 & 16 \\
\hline 12 & 0.5824 & 0.9295 & 0.9257 & 0.7943 & 5 \\
\hline 13 & 0.2711 & 0.7873 & 0.9752 & 0.5927 & 8 \\
\hline 14 & 0.3256 & 0.5755 & 0.9882 & 0.5700 & 9 \\
\hline 15 & 0.3252 & 0.9237 & 0.9396 & 0.6560 & 6 \\
\hline 16 & 0.2656 & 0.6217 & 0.9590 & 0.5410 & 11 \\
\hline
\end{tabular}

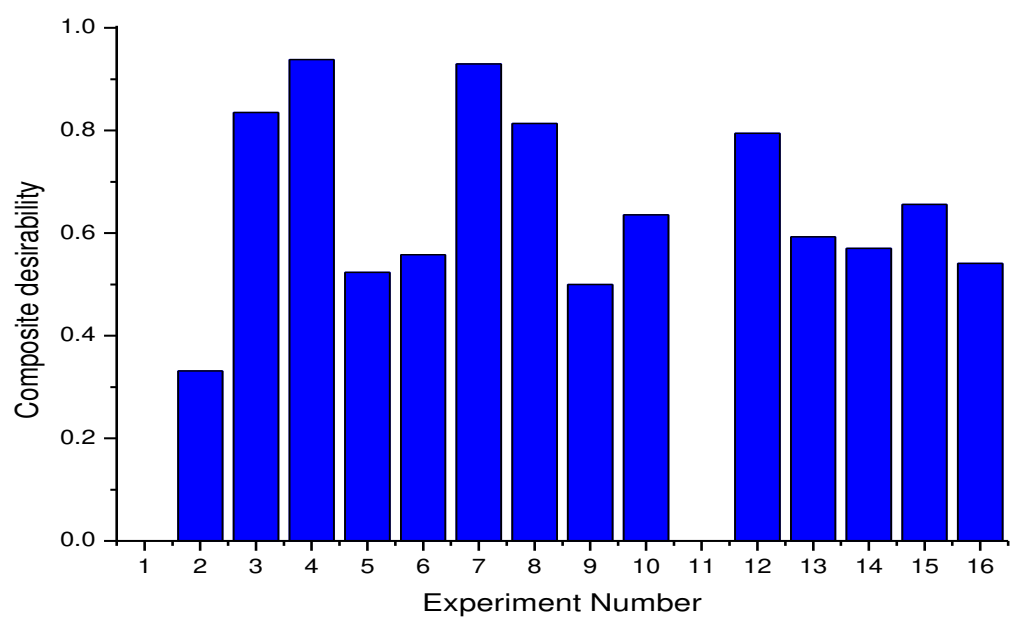

Fig. 3 Rank plot for composite desirability 
Figure 3 demonstrates the composite desirability versus experiment number and it was noticed that the Ex No 4 has a higher composite desirability (0.9382), which consists of a optimal combination of parameters are cutting speed $-200 \mathrm{rpm}$, feed rate $-50 \mathrm{~mm} / \mathrm{min}$ and depth of cut $-1.6 \mathrm{~mm}$.

\section{Results and Discussion}

\subsection{Analysis of GRG}

The response table for mean GRG at each level of input parameters is presented in Table 7. From the table, the impact of parameter was determined by the delta $(\Delta)$ value. The maximum delta value represented the high impact parameter on the response. According to the table 7, it was found that depth of cut was the most significant factor, followed by feed rate and cutting speed respectively.

Table 7 Response table for mean GRG

\begin{tabular}{|c|c|c|c|c|c|c|}
\hline \multirow{2}{*}{$\begin{array}{c}\text { Machining } \\
\text { Parameter }\end{array}$} & $\mathbf{1}$ & $\mathbf{2}$ & $\mathbf{3}$ & $\mathbf{4}$ & \multirow{2}{*}{ Delta $(\Delta)$} & Rank \\
\cline { 2 - 7 } & 0.6530 & 0.7391 & 0.7058 & 0.6741 & 0.0862 & 3 \\
\hline V & 0.6036 & 0.6374 & 0.7722 & 0.7588 & 0.1687 & 2 \\
\hline F & 0.5514 & 0.6942 & 0.7094 & 0.8170 & 0.2655 & 1 \\
\hline D & \multicolumn{7}{|c|}{} & \\
\hline \multicolumn{2}{|l|}{ Mean GRG $=0.6929$}
\end{tabular}

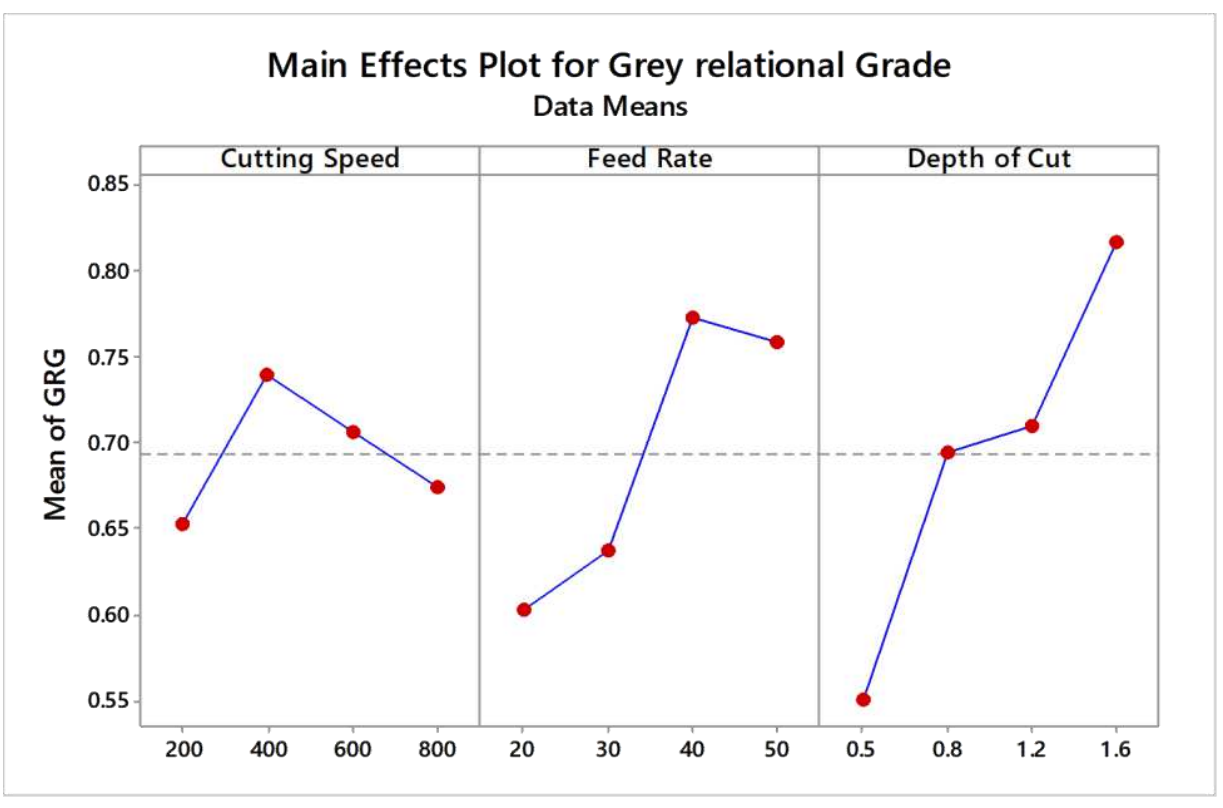

Fig. 4 Main effect plot for GRG 
The main effect plot of milling parameters on mean GRG is shown in Fig. 4. From the graph, the $\mathrm{x}$ - axis indicates the level of milling parameters and $\mathrm{y}$ - axis indicates the mean GRG. The middle dotted line indicates the average mean GRG. According to the Fig. 4, it was obviously found that the optimum level of parameter for maximum GRG obtained are $\mathrm{V}_{2} \mathrm{~F}_{3} \mathrm{D}_{4}$, which means that the cutting speed at level $2(400 \mathrm{rpm})$, feed rate at level $3(40 \mathrm{~mm} / \mathrm{min})$ and depth of cut at level $4(1.6 \mathrm{~mm})$.

Table 8 ANOVA for GRG

\begin{tabular}{|c|c|c|c|c|c|c|}
\hline $\begin{array}{c}\text { Machining } \\
\text { Parameter }\end{array}$ & DF & Seq.SS & Adj.SS & Adj.MS & F-ratio & P-value \\
\hline V & 3 & 0.017014 & 0.017014 & 0.005671 & 0.94 & 0.478 \\
\hline F & 3 & 0.086820 & 0.086820 & 0.028940 & 4.80 & 0.049 \\
\hline D & 3 & 0.142721 & 0.142721 & 0.047574 & 7.89 & 0.017 \\
\hline Error & 6 & 0.036177 & 0.036177 & 0.006030 & -- & -- \\
\hline Total & 15 & 0.282731 & -- & -- & -- & - \\
\hline
\end{tabular}

(DF- Degrees of Freedom, Seq. SS- Sequential Sum of Square, Adj. SS - Adjusted Sum of Square, Adj. MS - Adjusted Mean Square)

ANOVA is a statistical technique employed to determine the effects of parameters on the response under investigation [20]. In this proposed study, ANOVA was employed to determine the impact of parameters viz. cutting speed (V), feed rate (F) and depth of cut (D) on GRG. The results of ANOVA for GRG are depicted in Table 8. As a rule, the P-value of parameter is less than 0.05 , which is statistically significant. From table 8 , it was understood that the P-value of depth of cut (P-0.017) and feed rate (0.049) was less than 0.05, which are more dominant factors on the GRG. The similar observation was previously reported by Ugur koklu et al. [21]. Figure 5 illustrates the contribution of milling parameter on the GRG. It was visibly found that, the depth of cut was the most predominant factor on GRG with contribution of $50.48 \%$, trailed by feed rate with contribution of $30.71 \%$ respectively. The residuals are evenly disseminated in the confidence level shown in Fig. 6. 


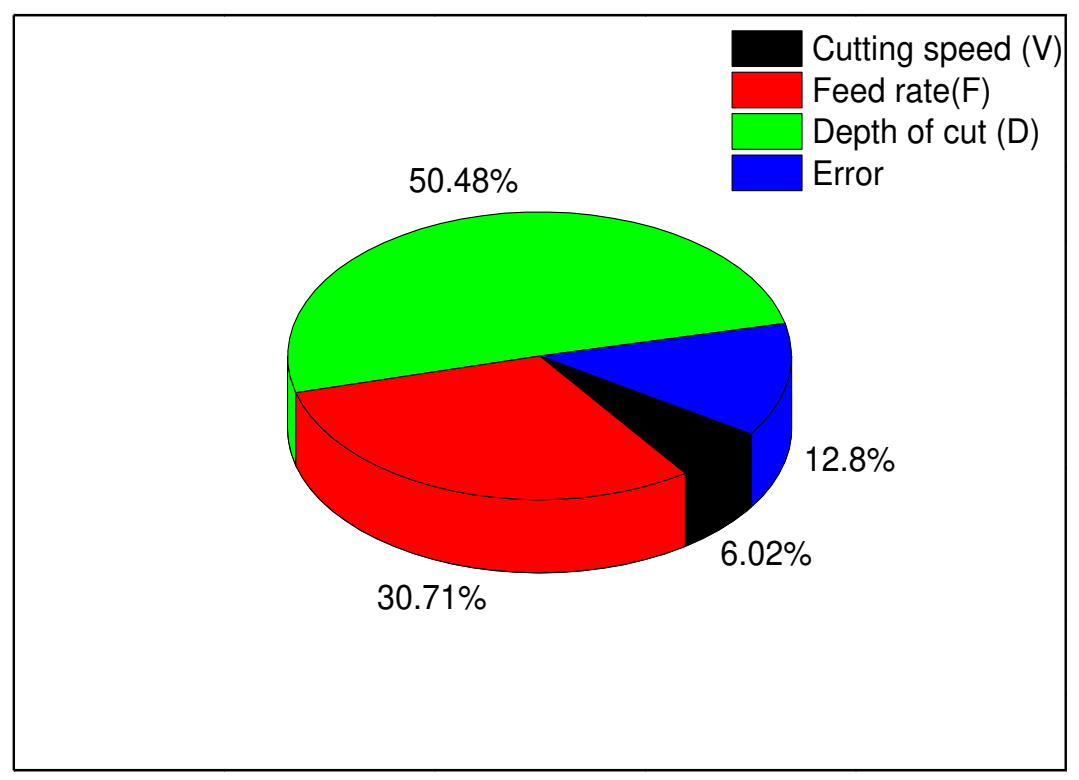

Fig. 5 Contribution plot of GRG

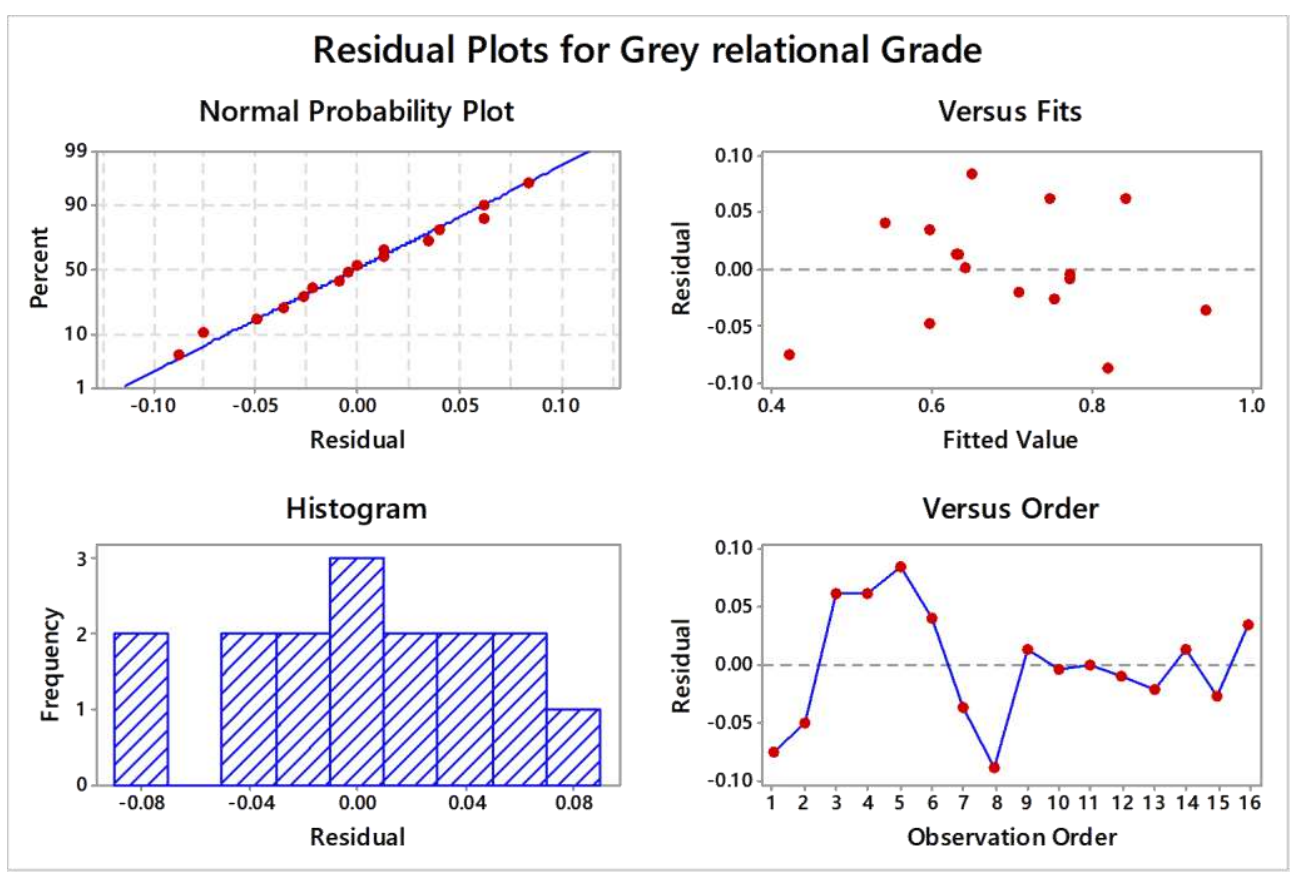

Fig. 6 Residual plot of GRG

\subsection{Analysis of Composite Desirability (dG)}

The response table for mean composite desirability at each level of input parameters is provided in Table 9. From the table, the significant of parameter was obtained from the delta $(\Delta)$ value. The maximum delta $(\Delta)$ value denoted the more significant parameter on the 
responses. From table 7, it was understood that depth of cut was the most impact factor, followed by feed rate and cutting speed respectively.

Table 9 Response table for mean composite desirability

\begin{tabular}{|c|c|c|c|c|c|c|}
\hline \multirow{2}{*}{$\begin{array}{c}\text { Machining } \\
\text { Parameter }\end{array}$} & $\mathbf{1}$ & $\mathbf{2}$ & $\mathbf{3}$ & $\mathbf{4}$ & \multirow{2}{*}{ Delta $(\Delta)$} & Rank \\
\cline { 2 - 7 } & 0.5262 & 0.7062 & 0.4824 & 0.5899 & 0.2239 & 3 \\
\hline V & 0.4039 & 0.5239 & 0.6052 & 0.7717 & 0.3678 & 2 \\
\hline F & 0.2748 & 0.5763 & 0.6795 & 0.7741 & 0.4993 & 1 \\
\hline D & \multicolumn{7}{|l|}{} \\
\hline
\end{tabular}

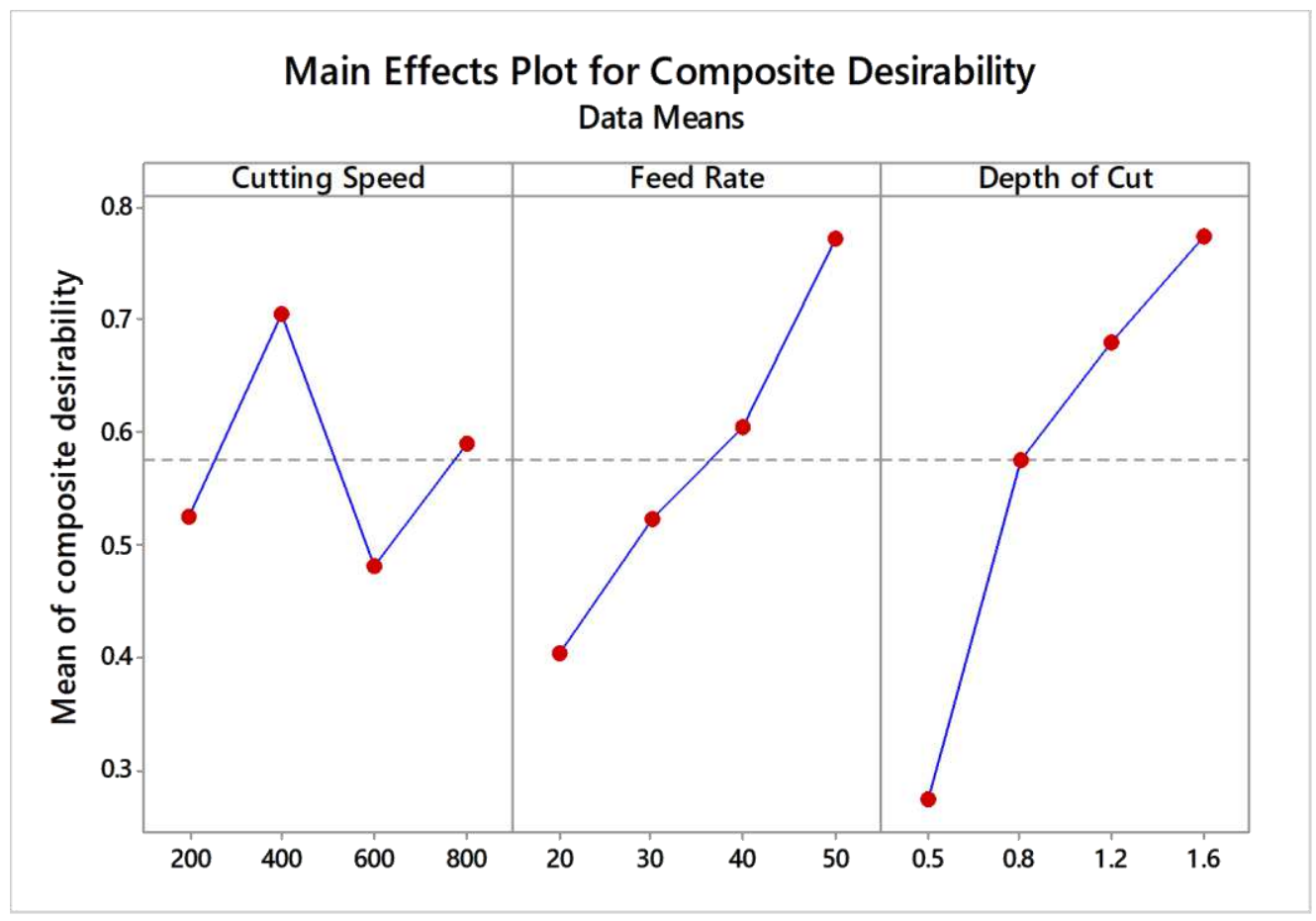

Fig. 7 Main effect plot for composite desirability

The main effect plot of milling parameters on mean composite desirability is illustrated in Fig. 7. From the graph, the $\mathrm{x}$ - axis indicates the level of input parameters and $\mathrm{y}$ - axis indicates the mean composite desirability $\left(\mathrm{d}_{\mathrm{G}}\right)$. The centre dot line indicates the average mean desirability value. From Fig. 7, it was clearly revealed that the optimum level of parameter for maximum composite desirability value obtained are $\mathrm{V}_{2} \mathrm{~F}_{4} \mathrm{D}_{4}$, which means that the cutting speed at level $2(400 \mathrm{rpm})$, feed rate at level $4(50 \mathrm{~mm} / \mathrm{min})$ and depth of cut at level 4 (1.6 $\mathrm{mm})$. 
Table 10 ANOVA for composite desirability

\begin{tabular}{|c|c|c|c|c|c|c|}
\hline $\begin{array}{c}\text { Machining } \\
\text { Parameter }\end{array}$ & DF & Seq.SS & Adj.SS & Adj.MS & F-ratio & P-value \\
\hline V & 3 & 0.11359 & 0.11359 & 0.03786 & 1.09 & 0.423 \\
\hline F & 3 & 0.28595 & 0.28595 & 0.09532 & 2.74 & 0.136 \\
\hline D & 3 & 0.56272 & 0.56272 & 0.18757 & 5.39 & 0.039 \\
\hline Error & 6 & 0.20889 & 0.20889 & 0.03481 & -- & -- \\
\hline Total & 15 & 1.17115 & -- & -- & -- & - \\
\hline
\end{tabular}

ANOVA results for composite desirability $\left(\mathrm{d}_{\mathrm{G}}\right)$ value are given in Table 10 . As a rule, the Pvalue of parameter is less than 0.05 , which is statistically significant. From table 10, it was noticed that the P- value of depth of cut (P-0.039) was less than 0.05 , which is major noteworthy factor on the composite desirability $\left(\mathrm{d}_{\mathrm{G}}\right)$. Figure 8 illustrates the graphical contribution of milling parameter on the composite desirability $\left(\mathrm{d}_{\mathrm{G}}\right)$. It can be observed that, the depth of cut was the primary impact factor with contribution of $48.05 \%$, subsequently by feed rate and cutting speed with contributions of $24.42 \%$ and $9.7 \%$ respectively. Figure 9 display the residual plot for composite desirability.

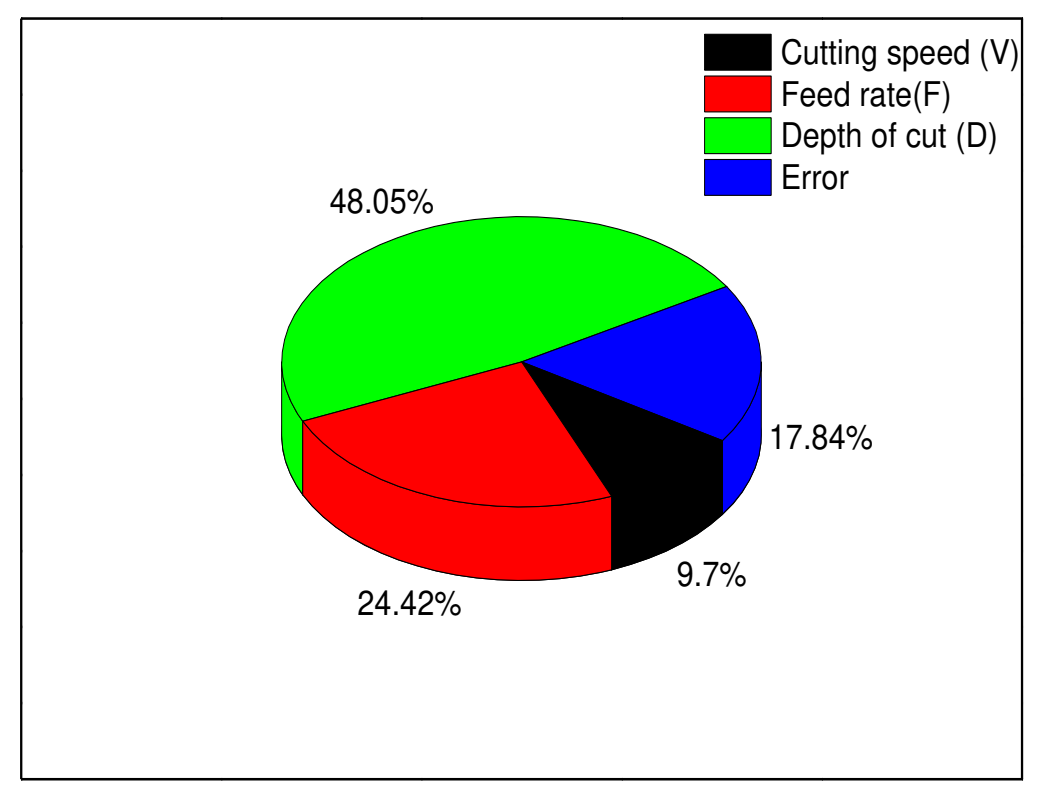

Fig. 8 Contribution plot of composite desirability 


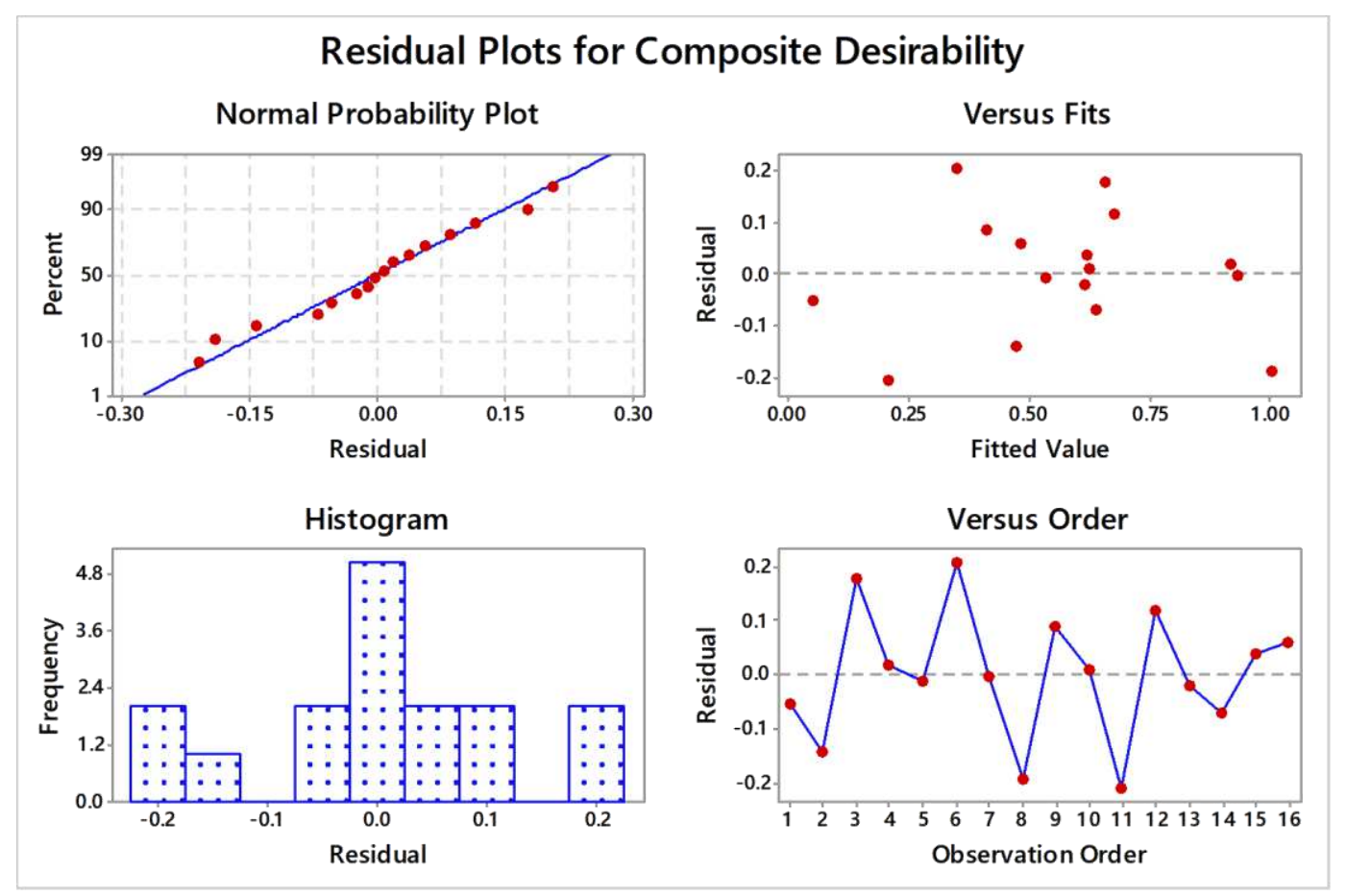

Fig. 9 Contribution plot of composite desirability

\subsection{Confirmation Tests}

The confirmation test was carried out at the optimum testing conditions on the response for the end milling process of GFRP composite. The predicted value of GRG and composite desirability $\left(\mathrm{d}_{\mathrm{G}}\right)$ is attained by Eq. (12). [22]

$$
\gamma_{\text {pre }}=\gamma_{m}+\sum_{k=1}^{n}\left(\gamma_{i}-\gamma_{m}\right)
$$

The summary of the obtained results from the confirmation tests are provided in Table $11 \&$ 12. The GRG and composite desirability $\left(\mathrm{d}_{\mathrm{G}}\right)$ value of the initial parameters to the optimal parameters has been improved at 0.3564 and 0.6060 respectively.

Table 11 Confirmation results (GRA)

\begin{tabular}{|l|c|c|c|}
\hline \multirow{2}{*}{$\begin{array}{l}\text { Responses / Optimal } \\
\text { Level }\end{array}$} & Initial & Predicted value & Experimental value \\
\cline { 2 - 4 } MRR $(\mathrm{g} / \mathrm{min})$ & $\mathrm{V}_{1} \mathrm{~F}_{1} \mathrm{D}_{1}$ & $\mathrm{~V}_{2} \mathrm{~F}_{3} \mathrm{D}_{4}$ & $\mathrm{~V}_{2} \mathrm{~F}_{3} \mathrm{D}_{4}$ \\
\hline $\mathrm{SR}(\mu \mathrm{m})$ & 0.483471 & - & 0.955414 \\
\hline TWR $(\mathrm{g} / \mathrm{min})$ & 0.111 & - & 1.513 \\
\hline GRG & 0.5496 & 0.942316 & 0.00063 \\
\hline Improvement of GRG $=0.3564$ & - & 0.9060 \\
\hline
\end{tabular}


Table 12 Confirmation results (DFA)

\begin{tabular}{|l|c|c|c|}
\hline \multirow{2}{*}{ Responses / Optimal Level } & Initial & Predicted value & Experimental value \\
\cline { 2 - 4 } & $\mathrm{V}_{1} \mathrm{~F}_{1} \mathrm{D}_{1}$ & $\mathrm{~V}_{2} \mathrm{~F}_{4} \mathrm{D}_{4}$ & $\mathrm{~V}_{1} \mathrm{~F}_{4} \mathrm{D}_{4}$ \\
\hline MRR $(\mathrm{g} / \mathrm{min})$ & 0.4834 & - & 1.1629 \\
\hline $\mathrm{SR}(\mu \mathrm{m})$ & 6.111 & - & 2.285 \\
\hline $\mathrm{TWR}(\mathrm{g} / \mathrm{min})$ & 0.0053 & - & 0.0022 \\
\hline Composite desirability & 0.3316 & 1.0998 & 0.9382 \\
\hline \multicolumn{2}{|l}{ Improvement of composite desirability $\left(\mathrm{d}_{\mathrm{G}}\right)=0.6066$} \\
\hline
\end{tabular}

\section{Conclusions}

The subsequent conclusions were drawn from the present investigations:

- The GR and DF approach was successfully employed for optimizing the end milling parameters on GFRP composite material.

- The optimized level of the parameters obtained by GR analysis are:

Cutting speed, V - 400 rpm;

Feed rate, $\mathrm{F}-40 \mathrm{~mm} / \mathrm{min}$;

Depth of cut, D - $1.6 \mathrm{~mm}$.

- The optimized level of the parameters obtained by DF approach are:

Cutting speed, V - 200 rpm;

Feed rate, $\mathrm{F}-50 \mathrm{~mm} / \mathrm{min}$;

Depth of cut, D - $1.6 \mathrm{~mm}$.

- For the optimized parameters, the machined GFRP composite materials exhibited higher the MRR and lower the SR and TWR.

- From ANOVA results, it has been ensured that the depth of cut was the major contributing parameter on the multiple responses, followed by feed rate and cutting speed respectively.

- Based on the confirmation experiments, DF analysis employed better in terms of determining optimum level of milling parameters compared to GR analysis. 


\section{References}

1. A.I. Azmi, R. J. T. Lin and D. Bhattacharyya, Experimental study of machinability of GFRP composites by end milling. Mater.Manuf. Process. vol. 27, 1045-1050 (2012)

2. I. S. N. V. R. Prashanth, D. V. Ravi Shankar, M. Manzoor Hussain, B. Chandra Mouli, Critical analysis in milling of GFRP composites by various end mill tools. Mater.Today: Proceed. 5(6), 14607-14617 (2018)

3. H. Hocheng, H.Y. Puw and Y. Huang, Preliminary study on milling of unidirectional carbon fiber reinforced plastics, Compos. Manuf. 4(2), 103-108 (1993)

4. K. Palanikumar, L. Karunamoorthy, R. Karthikeyan, Assessment of factors influencing surface roughness on the machining of glass fiber-reinforced polymers composites. Mater. Des. (27), 862-871 (2006)

5. G. C. Everstine and T. G. Rogers, A theory of machining of fiber-reinforced materials. J. Compos. Mater. (5), 91-106 (1971)

6. P. Raveendran and P. Marimuthu, Multi-response optimization of turning parameters for machining glass fiber-reinforced plastic composite rod. Adv. Mech. Eng. 7(12), $1-10(2015)$.

7. A. K. Parida and B. C. Routara, Multiresponse optimization of process parameters in turning of GFRP using TOPSIS method. International Scholarly Research Notices. 2014, 1-10 (2014)

8. H. Naresh and P. C. Prasad, lathe parameters optimization for UD-GFRP composite part turning with PCD tool by Taguchi method. INCAS. Bull. 12(4), 135 - 144 (2020)

9. A. Naveen Sait and S. Aravindan, A. Noorul Haq, Optimisation of machining parameters of glass-fibre-reinforced plastic (GFRP) pipes by desirability function analysis using Taguchi technique. Int. J. Adv. Manuf. Technol. 43, 581-589 (2009)

10. M. P. Jenarthanan and R. Jeyapaul, Optimisation of machining parameters on milling of GFRP composites by desirability function analysis using Taguchi method. Int. J. Eng. Sci. Technol. 5(4), 23-36 (2013)

11. K. Palanikumar, L. Karunamoorthy, R. Karthikeyan and B. Latha, Optimization of machining parameters in turning GFRP composites using a carbide (K10) tool based on the Taguchi method with fuzzy logics. Met. Mater. Int. 12(6), 483-491 (2006)

12. S. Ghalme, Ankush Mankar and Y. J. Bhalerao, Parameter optimization in milling of glass fiber reinforced plastic (GFRP) using DOE-Taguchi method. Springer Plus. 5, 19 (2016) 
13. A. Sharma, M. L. Aggarwal and L. Singh, Investigation of GFRP gear accuracy and surface roughness using Taguchi and grey relational analysis. J. Adv. Manuf. Syst. 19(1), 147-165 (2020)

14. R. K. Verma, K. Abhishek, S. Datta, P. K. Pal and S. S. Mahapatra, Multi-response optimization in machining of GFRP (Epoxy) composites: an integrated approach. J. Manuf. Sci. Prod. 15, 1-26 (2015)

15. E. K. Mohammed Yaser, K Shunmugesh, Multi-objective optimization of milling process parameters in glass fibre reinforced polymer via grey relational analysis and desirability function. Mater. Today: Proceed. 11, 1015-1023 (2019)

16. K. Palanikumar, L. Karunamoorthy and R. Karthikeyan, Multiple performance optimization of machining parameters on the machining of GFRP composites using carbide (K10) tool. Mater. Manuf. Process. 21, 846-852 (2006)

17. V. K. Vankanti, V. Ganta, Optimization of process parameters in drilling of GFRP composite using Taguchi method. J. Mater. Res. Technol. 3(1), 35-41 (2014)

18. J. L. Deng, Introduction to Grey system. J. Grey System. 1, 1-24 (1989)

19. S. V. Alagarsamy, M. Ravichandran, S. Dinesh Kumar, et al., Taguchi coupled desirability function analysis of wire cut EDM behaviour of titanium dioxide filled aluminium matrix composite. Mater. Today: Proceed. 27, 853-858 (2020)

20. S. V. Alagarsamy and M. Ravichandran, Investigations on tribological behaviour of $\mathrm{AA} 7075-\mathrm{TiO}_{2}$ composites under dry sliding conditions. Ind. Lubr. Tribol. 71(9), 1064-1071 (2019)

21. Ugur Koklu, Murat Mayda, Sezer Morkavuk, et al., Optimization and prediction of thrust force, vibration and delamination in drilling of functionally graded composite using Taguchi, ANOVA and ANN analysis. Mater. Res. Express. 6, 1-12 (2019)

22. C. C. Tsao, Grey-Taguchi method to optimize the milling parameters of aluminium alloy. Int. J. Adv. Manuf. Technol. 40, 41-48 (2009) 